\title{
Effect of Chronic Reserpine Treatment on the Pancreases of Neonatal Rats
}

\author{
K. S. CHUNG, P. C. LEE, S. BROOKS, AND E. LEBENTHAL \\ Division of Gastroenterology and Nutrition, Children's Hospital of Buffalo, Department of Pediatrics, State \\ University of New York at Buffalo, Buffalo, New York 14222
}

\begin{abstract}
Chronic reserpine treatment of adult rats results in the accumulation of pancreatic enzymes and reduction of their discharge. These changes are reminiscent of those in cystic fibrosis. Since the majority of cystic fibrosis patients have their pancreatic dysfunction manifested in childhood, we studied chronic reserpine treatment in rat pups. Four-day-old rat pups were given reserpine (50 $\mu \mathrm{g} / \mathrm{kg}$ intraperitoneally) or vehicle daily until sacrifice. The reserpine group showed significant decreases in body weights at 14 and 21 days of age. Pancreatic weights were also decreased but were of normal weight or increased when normalized against body weights. At 14 and 21 days of age, pancreatic concentrations of amylase, lipase, and trypsinogen showed no difference between reserpine and control pups. At both ages, pancreatic contents of all three enzymes were generally less in the treated pups, but were found to be similar when corrected for body weights. Hydrocortisone treatment of 14-day-old pups caused precocious accumulation of pancreatic enzymes in both reserpine and control groups.

Intestinal contents of lipase, trypsin, and amylase were decreased in the reserpine pups at 14 days of age and reached a more significant level at 21 days of age; these data suggest a decrease in the secretion of pancreatic enzymes. Dispersed acini from 14-day-old pups showed a reduced capacity to release amylase as stimulated by carbachol or the octapeptide of cholecystokinin. The results suggested that chronic reserpine treatment of pups in the suckling period did not cause significant disturbance of the developmental accumulation of pancreatic enzymes. A definite inhibition of exocrine secretion was found with reserpine treatment. In terms of suppression of enzyme secretion, the results with reserpinized pups resemble the conditions found in cystic fibrosis. (Pediatr Res 18:1300-1304, 1984)
\end{abstract}

In adult rats, chronic administration of reserpine produces characteristic morphological and biochemical changes in the exocrine pancreas. Morphological changes include an accumulation of secretory granules and a slight reduction in rough endoplasmic reticulum in acinar cells $(14,17)$. Granule discharge is reduced upon stimulation with cholecystokinin and is accompanied by the appearance of numerous autophagic bodies (17). Zymogen granules isolated from the pancreases of reserpine-

Received February 2, 1984: accepted June 5, 1984.

Requests for reprints should be addressed to Dr. P. C. Lee. Division of Gastroenterology and Nutrition. Children's Hospital of Buffalo, 219 Bryant Street. Buffalo, NY 14222.

This research was supported in part by National Institutes of Health Grant HD 12586. treated rats have higher specific activities of proteases as compared to control animals. This has been interpreted as an increase of biosynthesis and of intracellular tranport of proteins (10). The in vivo secretory response to stimulation with caerulein is characteized by a decrease in volume and amylase output (1). In many ways, the pancreatic dysfunction in chronically treated rats resembles that found in the pancreases of cystic fibrosis patients and therefore has been proposed as an experimental model for the disease (6). Since a majority of CF patients have their pancreatic symptoms manifested early in life $(18,19)$, it may be more appropriate to examine the animal model at a much younger developmental stage. We undertook the following study to investigate the effect of chronic administration of reserpine on the pancreases of suckling rats by assessing (i) their ability to accumulate pancreatic enzymes, (ii) their responses to precocious induction with hydrocortisone, and (iii) their secretory functions in vivo and in vitro.

\section{MATERIALS AND METHODS}

Pregnant mothers of Sprague-Dawley rats were obtained commercially on the 15 th day of gestation and housed individually with a 12-h light/dark cycle. The day of birth was taken as day 0 . At day 1 , all pups were removed, pooled, and redistributed such that each mother had 12 pups (normal litter size, 14-16). Each mother with her group of pups was housed separately. Dams were fed laboratory chow (Wayne Lab Blox, Allied Mills, Inc., Chicago, IL) and water ad libitum.

Protocol. At day 4, pups were removed, pooled, and separated into two groups. The experimental group was given daily doses of reserpine $(50 \mu \mathrm{g} / \mathrm{kg} /$ day $)$ by intraperitoneal injection. A higher dose was not used since it led to gross malnutrition since the pups reduced or stopped suckling. A stock solution of reserpine (Sigma Chemical Company St. Louis, MO) was made according to the method of Forstner et al. (5) by dissolving the drug in acetic acid and propylene glycol. A control group consisting of age-matched pups received the same volume of solvent delivered in an identical manner. Pups were allowed to nurse normally and were not disturbed except for the daily injection. Injection was given until the day before sacrifice. The following experiments were performed.

Normal develoment. Pups were sacrificed at days 14 and 21 after birth. Their pancreases and intestinal contents were collected as descibed below. Pancreases were used for enzyme, DNA, and protein determination. Only the pancreases from 14-day-old pups were used to prepare dispersed acini for in vitro secretagogue stimulation assay. The entire liver was also removed and weighed for organ size comparison.

Precocious development. At day 12, half the number of pups from each of both control and reserpine-treated groups were injected with one dose of hydrocortisone $(5 \mathrm{mg} / 100 \mathrm{~g}$ of body weight) intramuscularly. At day 14, all pups were killed by 
decapitation and their pancreases were removed for subsequent assays.

Collection of intestinal contents. The whole small intestine from the pylorus to the ileocecal region was removed. Intestinal contents were collected by flushing with $2 \mathrm{ml}$ of chilled normal saline through the lumen.

Preparation of samples. Pancreatic tissue was minced with a sharp scissors. Tissue preparations and intestinal contents were then separately homogenized with a Potter-Elvehjem homogenizer using a motor-driven Teflon pestle with the vessel immersed in crushed ice. Pancreatic homogenates and samples of intestinal contents were sonicated before use for subsequent biochemical determinations.

Biochemical determinations. Protein was determined by the technique of Lowry et al. (9) using bovine serum albumin fraction $\mathrm{V}$ as the standard. DNA was measured by the colorimetric reaction with diphenylamine reagent according to Burton (2) by using highly polymerized calf thymus DNA as the standard. A modified procedure was adapted to minimize the interference by sialic acids according to Croft and Lubran (3).

Trypsinogen was first activated with enterokinase, at a constant ratio of enterokinase/homogenate proteins for $45 \mathrm{~min}$ at $25^{\circ} \mathrm{C}$; these conditions have yielded optimal and reproducible activation of this zymogen in our laboratory. The enterokinase used was partially purified from mucosa of the proximal small intestine of rats following the procedure of Baratti et al. (1) up to the acidification step. Trypsin activity was then measured from the hydrolysis of $p$-nitroaniline from the substrate benzoyl-DL-arginine $p$-nitroanilide at $\mathrm{pH} 8.2$ and $25^{\circ} \mathrm{C}$ (4). Units are expressed as nanomoles of substrate hydrolyzed per $\mathrm{min} / \mathrm{mg}$ of protein. Lipase activity was determined by potentiometric titration (at a constant $\mathrm{pH}$ of 8 ) of ionized fatty acid liberated from an olive oil emulsion (16). Units are expressed as micromoles of $\mathrm{NaOH}$, required to neutralize the free fatty acid, liberated per $\mathrm{min} / \mathrm{mg}$ of protein. Amylase was determined by the saccharogenic method (15) by using soluble starch as the substrate. Units are expressed as micromoles of maltose liberated per $\mathrm{min} / \mathrm{mg}$ of protein.

Preparation of dispersed acini and in vitro assay of secretagogue-stimulated amylase release. Dispersed acini from the rat pancreas were prepared according to a previously published procedure (7). The standard incubation medium contained 25 mM $N$-2-hydroxyethylpiperazine- $N^{\prime}$-2-ethanesulfonic acid (pH 7.4), $98 \mathrm{mM} \mathrm{NaCl}, 6 \mathrm{mM} \mathrm{KCl}, 2.5 \mathrm{mM} \mathrm{NaH}_{2} \mathrm{PO}_{4}, 5 \mathrm{mM} \mathrm{Na}$ pyruvate, $5 \mathrm{mM}$ fumarate, $5 \mathrm{mM} \mathrm{Na}$ glutamate, $11.5 \mathrm{mM}$ glucose, $0.5 \mathrm{mM} \mathrm{CaCl}_{2}, 2 \mathrm{mM}$ glutamine, $5 \mathrm{mM}$ theophylline, $1 \%$ (wt/vol) albumin, $0.1 \%$ (wt/vol) soybean trypsin inhibitor, $1 \%$ (vol/vol) essential amino acid mixture, and $1 \%$ (vol/vol) essential vitamin mixture. The release of amylase into the extracellular medium in the presence and absence of secretagogue was measured as reported previously (7). In all incubations, the gas phase was $100 \% \mathrm{O}_{2}$ and all the solutions were equilibrated with $100 \% \mathrm{O}_{2}$. To ensure uniformity in the treatment of the acini, pancreases from both control and treated rats were treated simultaneously with the same batch of purified collagenase (twice with 46 units in $3 \mathrm{ml}$ of buffer for $7 \mathrm{~min}$ each time).

Amylase release was measured as the percentage of amylase activity in the acini at the beginning of the incubation that was released into the extracellular medium during a 15-min incubation with and without secretagogues. All incubations with the secretagogue were done in triplicate. For each experiment, 2-3 pups were sacrificed.

Statistics. All results are presented as mean \pm SD. Differences between any two groups were evaluated by unpaired Student's $t$ test with $p<0.05$ considered as significant.

\section{RESULTS}

The developmental changes in body weight and other somatic parameters of the pancreas are summarized in Table 1. Chronic reserpine treatment led to significant decreases in body weight in both 14- and 21-day-old pups. In reserpine-treated pups, the total pancreatic mass showed a slight decrease at 14 days which became significant in one experimental group at 21 days. However, when the data were corrected for body weight (i.e. expressed as weight of pancreas/ $100 \mathrm{~g}$ of body weight), relative pancreatic weight on average was increased. In comparison, the liver weights per animal exhibited a significant decrease in the reserpinetreated rats but showed no change after correction for body weight. Except for one experimental group where the trypsinogen concentration was higher in the 14-day-old reserpine pups, no changes in enzyme concentrations were detected between the control and treated pups (Table 2). The mean content of pancreatic enzymes showed a modest decrease in most cases. Again, when corrected for body weights, no consistent decrease in enzyme content in the pancreas was discerned. Administration of hydrocortisone to both control and treated pups at the 12th day of age caused significant increases in the pancreatic mass and in total protein and DNA content per pancreas in both reserpine and control pups at the age of 14 days (Table 3 ). Further, the magnitude of the increase in the treated pups was similar to that found in the control pups.

Both amylase and lipase concentrations were increased in the hydrocortisone-treated pups whether they were from the control or reserpine-treated groups. Trypsinogen concentration, however, showed minimal if any changes at all (Table 4). Total contents of these three enzymes were, however, increased reflecting an increase in the pancreatic mass and enzyme concentrations.

In order to evaluate the secretion of pancreatic enzymes by

Table 1. Effect of reserpine on the developmental changes in body, pancreas, and liver weight and total protein and DNA contents in pancreases of suckling rats*

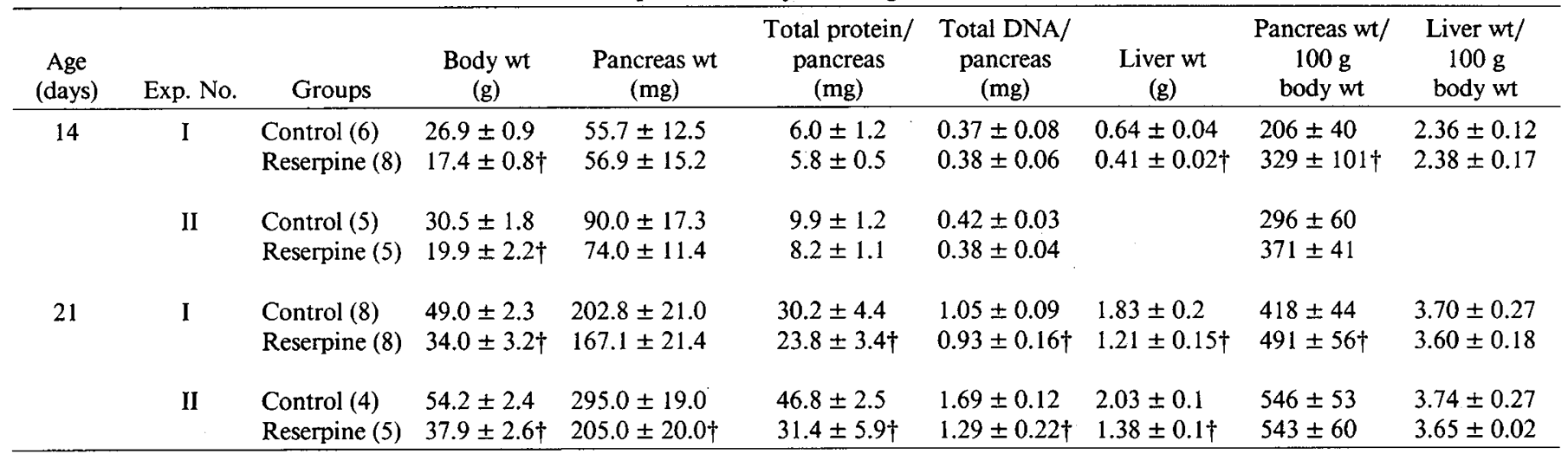

* Values are mean \pm SD. Numbers in parentheses denote the number of pups used in each group.

$\uparrow$ Significantly different from corresponding values of the control group from the same experiment $(p<0.05)$. 


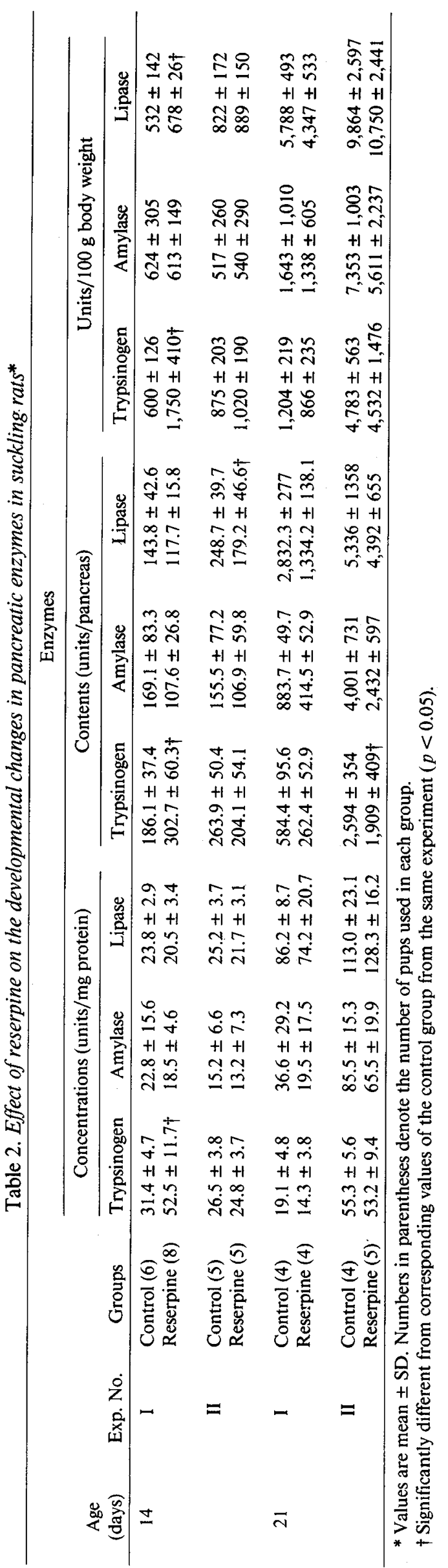

the control and reserpine-treated pups, total contents of pancreatic enzymes in the intestinal lumen were also measured. The results showed that reserpine treatment had a tendency to decrease the intestinal contents of trypsin, amylase, and lipase. To see if these were reflections of a decreased secretion by the pancreas, pancreatic acini were prepared from 14-day-old pups from both control and reserpine-treated groups and examined for their responsiveness to varying concentrations of carbachol and octapeptide of cholecystokinin. Figure 1 compares the secretory responses in terms of amylase release of the pancreas of the control pups and the reserpine-treated pups. With the pancreatic acini from control pups, typical dose-response profiles were seen with both secretagogues. With the pancreatic acini from reserpinized pups, a dose response was also seen but there were significant reductions in the percentage of amylase released at all concentrations of carbachol and at the three high concentrations (100, 300 , and $1000 \mathrm{pM}$ ) of octapeptide of CCK used.

\section{DISCUSSION}

Chronic administration of reserpine to adult rats has been shown to inhibit the secretion of fluid and bicarbonate from their exocrine pancreases $(12,13)$, and reduce the secretion of pancreatic enzymes in response to secretagogue stimulation (10). These conditions induced by chronic reserpine treatment are similar to those found in the pancreas of cystic fibrosis patients with accompanying pancreatic insufficiency. In humans, pancreatic dysfunction in cystic fibrosis more commonly develops in the early postnatal period $(18,19)$. Any disturbance should presumably occur during or before this stage. As such, it may be more appropriate to focus the effect during the suckling period in order to obtain further insight into its pathogenesis.

In this study, the treatment with reserpine of suckling rats starting at the age of 4 days resulted in general decreases in body weight, pancreatic weight, and total DNA and protein content of the pancreas at 14 and 21 days of age. These changes are superficially similar to those reported by Werlin et al. (21) who showed that short-term postnatal treatment (days 1 to 5) of reserpine in rat pups led to glandular hypoplasia. Our results also showed a smaller pancreas in the reserpine rats when compared to the age-matched controls. The same reduction in size was, however, also found in the liver. Further, when the pancreatic weights were normalized against corresponding body weights in both reserpine-treated and control pups, it showed an equal if not higher value in the case of the reserpine-treated pups. Similarly, the liver weights when normalized against the body weight also showed no difference between the two groups of pups. The results suggest that reserpine has no specific hypoplastic effect on the pancreas.

Our results showed that chronic administration of reserpine to suckling rats did not change the specific activities of trypsinogen, amylase, and lipase. In this regard, results differ from those with adult reserpine-treated rats which showed an increase in specific activities of protease (10). Apparent decreases of pancreatic contents of trypsinogen, amylase, and lipase were, however, seen in the reserpine-treated pups. When the values were corrected for the decreases in body weights, there were no differences detected. Thus, reserpine, at the dose and regimen used, did not hinder the natural development of the rat pancreas and its exocrine enzymes.

In normal postnatal development, the pancreas of the rat pup has been shown to accumulate amylase, trypsinogen, and lipase at weaning (14-22 days of age) and that hydrocortisone administration before weaning will induce the accumulation of these enzymes precociously $(8,11)$. Not only did the pancreases of the reserpine-treated pups exhibit normal accumulation of exocrine enzymes during a natural developmental cycle, but they also showed similar trophic responses to the administration of hydrocortisone. The effects of hydrocortisone in the pancreases in the preweanling rat pups have been well documented $(8,11,20)$. Basically, hydrocortisone induces a precocious increase in pancreatic mass and enzyme concentration, particularly that of 
Table 3. Effect of hydrocortisone on the developmental changes in body and pancreas weight and total protein and DNA contents in pancreases of reserpinized and control suckling rats*

\begin{tabular}{|c|c|c|c|c|c|c|}
\hline Exp. No. & Groups & Treatment & $\begin{array}{c}\text { Body wt } \\
(\mathrm{g})\end{array}$ & $\begin{array}{l}\text { Pancreas wt } \\
\text { (mg) }\end{array}$ & $\begin{array}{l}\text { Total protein/ } \\
\text { pancreas } \\
(\mathrm{mg})\end{array}$ & $\begin{array}{c}\text { Total DNA/ } \\
\text { pancreas } \\
(\mathrm{mg})\end{array}$ \\
\hline I & Control & $\begin{array}{l}\text { Saline (3) } \\
\text { Hydrocortisone (3) }\end{array}$ & $\begin{array}{l}30.1 \pm 9.2 \\
34.0 \pm 0.3\end{array}$ & $\begin{array}{l}69.7 \pm 4.6 \\
89.6 \pm 5.5 \dagger\end{array}$ & $\begin{array}{c}8.6 \pm 1.0 \\
13.2 \pm 0.6 \dagger\end{array}$ & $\begin{array}{l}0.47 \pm 0.08 \\
0.59 \pm 0.10 \dagger\end{array}$ \\
\hline & Reserpine & $\begin{array}{l}\text { Saline (3) } \\
\text { Hydrocortisone (3) }\end{array}$ & $\begin{array}{l}25.5 \pm 1.8 \\
27.1 \pm 1.6\end{array}$ & $\begin{array}{l}70.2 \pm 0.5 \\
82.8 \pm 5.4 \dagger\end{array}$ & $\begin{array}{c}9.0 \pm 0.9 \\
11.5 \pm 0.1 \dagger\end{array}$ & $\begin{array}{l}0.58 \pm 0.10 \\
0.80 \pm 0.20 \dagger\end{array}$ \\
\hline & Reserpine & $\begin{array}{l}\text { Saline (4) } \\
\text { Hydrocortisone (5) }\end{array}$ & $\begin{array}{l}24.3 \pm 1.4 \\
23.1 \pm 0.5\end{array}$ & $\begin{array}{l}56.5 \pm 7.1 \\
67.9 \pm 11.1 \dagger\end{array}$ & $\begin{array}{c}7.7 \pm 1.3 \\
11.0 \pm 1.6 \dagger\end{array}$ & $\begin{array}{l}0.50 \pm 0.08 \\
0.65 \pm 0.08 \dagger\end{array}$ \\
\hline
\end{tabular}

* Values are mean \pm SD. Numbers in parentheses denote the number of pups used in each group.

$\dagger$ Significantly increased from the values of the saline-injected counterparts of the same group $(p<0.05)$.

Table 4. Effect of hydrocortisone on the development changes in pancreatic enzymes in reserpinized and control suckling rats* Enzymes

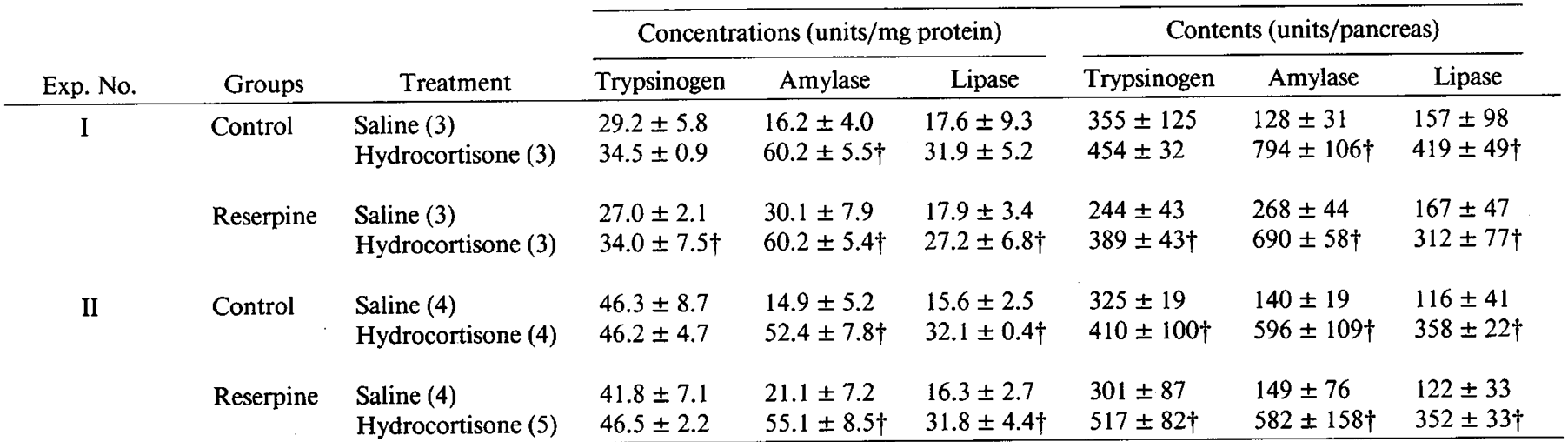

* Values are mean \pm SD. Numbers in parentheses denote the number of pups used in each group.

$\dagger$ Significantly increased from values of the saline-injected counterparts of the same group $(p<0.05)$.

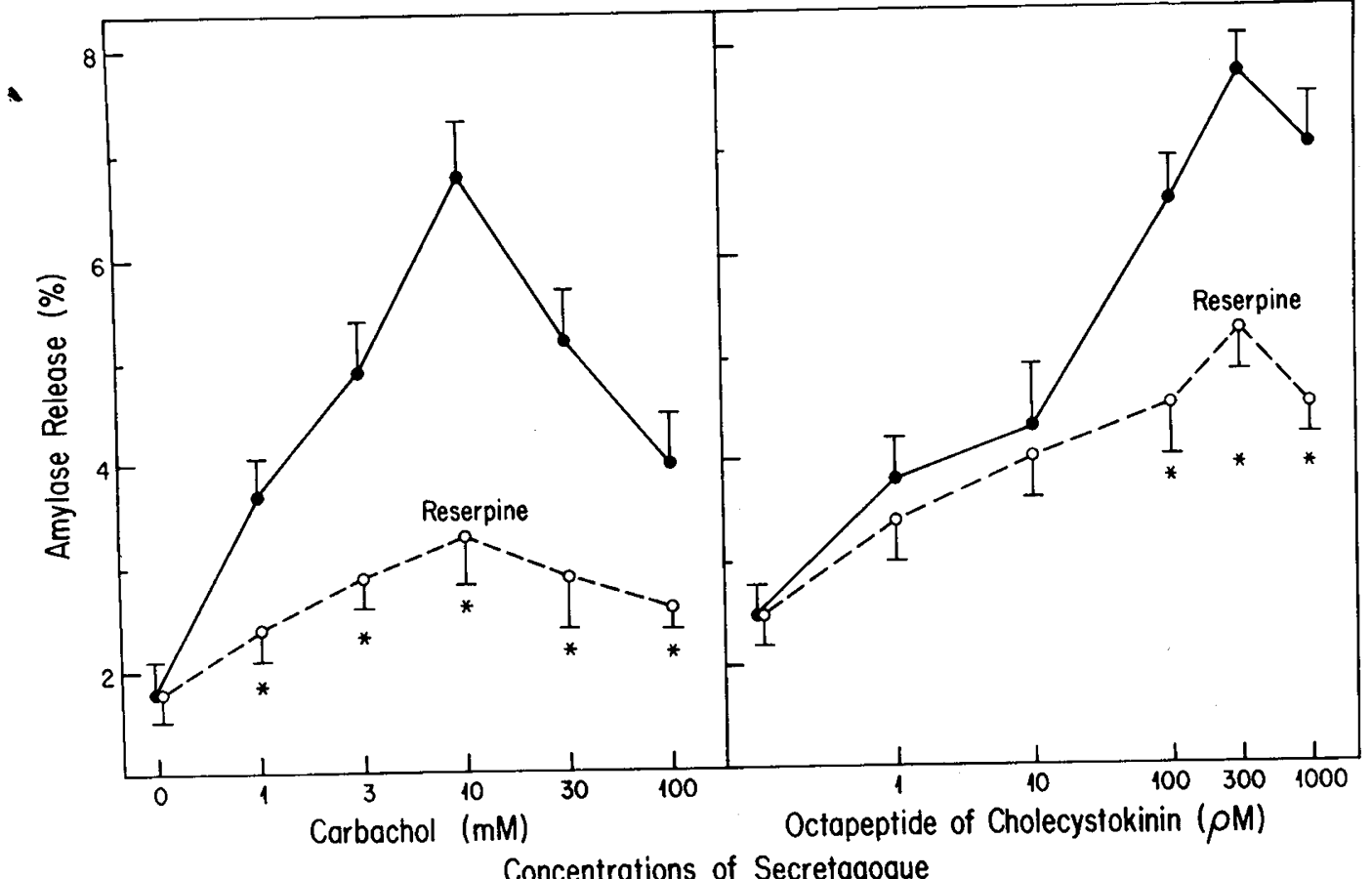

Fig. 1. Effect of chronic reserpine treatment on the in vitro responsiveness of dispersed pancreatic acini to stimulation with carbachol (left panel) and octapeptide of cholecystokinin (right panel). $\bullet$, values from control, vehicle-injected pups. $O$, values from chronic reserpine-injected pups. Both groups were sacrificed at 14 days of age. In each experiment for each time point, two to three pups from each group were used. Each dispersed acini preparation was performed in triplicate for each concentration of secretagogue used. Results given are means of three separate experiments. Astersisks denote values that are significantly lower than corresponding control values $(p<0.05)$. All values are presented as mean \pm SEM. 
amylase and lipase. In the present study, these hypertrophic effects were observed in both the control and reserpinized pups following hydrocortisone treatments. Thus, the pancreas of the reserpinized pups retained the basic capability of biosynthesis of pancreatic protein, DNA, and particularly the exocrine enzymes both during the normal chronological and in precocious development as induced by hydrocortisone.

The pancreases of the reserpine-treated rat pups were, however, not fully functional. The first hint was provided by the general decrease in pancreatic enzymes recovered from the small intestinal contents of these pups as compared to those obtained from control pups. This suggested a reduced secretory capacity by the pancreases of the reserpine-treated rat pups. Results from in vitro studies using dispersed acini prepared from the pancreases of the reserpine-treated and control pups demonstrated a decreased responsiveness in terms of amylase release of the acini from reserpine-treated pancreases as compared to those from control pancreases when subjected to stimulation by carbachol or octapeptide of cholecystokinin. In this particular aspect, the pancreases of the reserpine-treated pups are identical to those found in adult rats $(13,17)$.

Our results showed that chronic reserpine treatment of rat pups, at the dosage used, did not disturb their exocrine pancreatic development in terms of pancreatic mass corrected for body weights or of their concentrations and contents of pancreatic exocrine enzymes. As such, rat pups differ from adult reserpine-treated rats in that the latter showed a selective increase in their pancreatic proteases. The difference perhaps can be attributed to the much lower dose of reserpine used in our study (50 versus $500 \mu \mathrm{g} / \mathrm{kg}$ body weight) and/or more importantly, to the developmental stages of the animals. Reserpine treatment, however, significantly impaired the secretory capacity of the pancreatic acini in both the pup and the adult. Considering the results together, reserpine may have a specific and potent action that interferes with the stimulus-secretion coupling mechanism of the pancreatic acini. On the other hand, reserpine treatment led to significantly decreased body weight, suggesting, perhaps, a partial malnutrition which may also be the cause of reduced responsiveness of the pancreas to secretagogues.

Acknowledgments. We thank Sharon Morelli and Dr. L. Heitlinger for their help in the preparation of this manuscript and Ok Kim and Shari Kohut for their excellent technical assistance.

\section{REFERENCES}

1. Baratti J, Maroux S, Louvard D, Desnuelle P 1973 On porcine enterokinase. Further purification and some molecular properties. Biochim Biophys Acta 315:147

2. Burton K 1956 A study of the conditions and mechanism of the diphenylamine reaction for the calorimetric estimation of deoxyribonucleic acid. Biochem J $62: 315$

3. Groft DN, Lubran 1965 The estimation of deoxyribonucleic acid in the presence of sialic acid: application to analysis of human gastric washings. Biochem J 95:612

4. Erlanger DF, Kokowsky N, Cohen W 1961 The preparation and properties of two new chromogenic substrates of trypsin. Arch Biochem Biophys 95:271

5. Forstner J, Maxwell B, Roomi N 1981 Intestinal secretion of mucin in chronically reserpine-treated rats. Am J Physiol 241:G441

6. Lebenthal E, Lee PC 1982 Animal models for pancreatic insufficiency in cystic fibrosis. J Pediatr Gastroenterol Nutr 1:9

7. Lee PC, Brooks S, Lebenthal E 1982 Effect of fasting and refeeding on pancreatic enzymes and secretagogues responsiveness in rats. Am $\mathrm{J}$ Physiol 242:G2 15

8. Lee PC, Lebenthal E 1983 Role of corticoids independent of food intake in the premature increase in pancreatic enzyme activities following early weaning in rats. $J$ Nutr 113:1381

9. Lowry OH, Rosebrough NJ, Farr AL, Randall RJ 1951 Protein measurement with the Folin phenol reagent. J Biol Chem 193:265

10. McCurdy RE, Martinez R 1981 The chronically reserpinized rat as a model for cystic fibrosis: alterations in pancreatic enzyme secretion and storage. Pediatr Res 15:1308

11. Morisset J, Jolicoeur L 1980 Effect of hydrocortisone on pancreatic growth in rats. Am J Physiol 239:G95

12. Morton D, Parker A, Estrada P, Martinez JR 1980 Exocrine pancreatic secretion in rats treated with reserpine after stimulation with pilocarpine, dopamine, and caerulein. Pediatr Res 14:18

13. Perlmutter J, Martinez JR 1978 The chronically reserpinized rat as a possible model for cystic fibrosis. VII. Alterations in the secretory response to cholecystokinin and to secretin from the pancreas in vivo. Pediatr Res 12:188

14. Roomans GM, Wet X, Ceder O, Kollberg H 1982 The reserpinized rat in the study of cystic fibrosis: X-ray microanalysis of submandibular gland and pancreas. Ultrastruct Pathol 3:285

15. Searcy RL, Hayashi S, Berk JE 1966 A new microsaccharogenic method for serum amylase determination. Tech Bull Regist Med Technol 36:252

16. Semeriva M, Dufour C, Desnuelle P 1971 On the probable involvement of a histidine residue in the active site of pancreatic lipase. Biochemistry 10:2143

17. Setser ME, Spicer SS, Simson JAV, Adamson M, Martinez JR 1979 The effects of reserpine on the ultrastructure and secretory response of rat exocrine pancreas. Exp Mol Pathol 31:413

18. Talamo RC, Rosenstein BJ, Berninger RW 1983 Cystic fibrosis. In: Stanbury JB, Wyngaarden JB, Fredrickson DS, Goldstein JL, Brown MS (eds) The Metabolic Basis of Inherited Diseases, 5th ed. McGraw-Hill, New York, pp 1889-1917

19. Taussig LM, Boat TF, Dayton D, Fost N, Hammond K, Holtzman N, Johnson W, Kaback MM, Kennel J, Rosenstein BJ, Stolz WS, Trause MA 1983 Neonatal screening for cystic fibrosis. Pediatrics 72:741

20. Takeuchi T, Ogawa M, Furihata c, Kawachi T, Sugimura T 1977 Perinatal changes in amylase and serum corticosteroid levels in rats. Biochim Biophys Acta 497:657

21. Werlin SL, Harb JM, Stefaniak J, Taylor T 1983 Pancreatic structure and function in the immature reserpinized rat. Exp Mol Pathol 39:24 